\title{
Abia State Telehealth Initiative: A Novel Ingenuity
}

\author{
V. I. Okezie1, G. J. Ahukannah², O. Onuka², S. U. Omas³, C. Kanu³, A. Tega4, A. Macaulay4, \\ A. Folu ${ }^{4}$ \\ ${ }^{1}$ Government House Umuahia, Umuahia, Abia state, Nigeria \\ ${ }^{2}$ Ministry of Health, Umuahia, Abia state, Nigeria \\ ${ }^{3}$ Mungo Park Crescent, Abuja, Nigeria \\ ${ }^{4}$ Globacom-Nigeria, Abuja, Nigeria \\ Email: osimiri_1@yahoo.co.uk, onphil200@yahoo.co.uk,omas_ubiame@dialadocdirect.com, \\ kanu_chimere@dialadocdirect.com, tega.agofure@gloworld.com, akoko.alus@gloworld.com, folu.aderibigbe@gloworld.com
}

How to cite this paper: Okezie, V.I., Ahukannah, G.J., Onuka, O., Omas, S.U., Kanu, C., Tega, A., Macaulay, A. and Folu, A. (2021) Abia State Telehealth Initiative: A Novel Ingenuity. E-Health Telecommunication Systems and Networks, 10, 75-82. https://doi.org/10.4236/etsn.2021.103004

Received: May 19, 2021

Accepted: July 12, 2021

Published: July 15, 2021

Copyright $\odot 2021$ by author(s) and Scientific Research Publishing Inc. This work is licensed under the Creative Commons Attribution International License (CC BY 4.0).

http://creativecommons.org/licenses/by/4.0/

\begin{abstract}
In Nigeria, Universal health coverage has been sub-optimal due to limited access and inequality. This is worsened by poor health-seeking behavior due to out-of-pocket expenditure health system financing being practiced by a greater percentage of the population. However, leveraging on the increasing population of Nigerian's using communication technologies provides a viable and robust platform for improving patient's care. Consequently, tele-health initiative provides a complementary approach to improving access to quality health and universal health system coverage. Tele-health initiative is Abia state's input in progressing the Universal Health Coverage mandate of the Federal Government of Nigeria, anchored on the e-Health policy of Nigeria, after its adoption at the 58th $\mathrm{NCH}$ in Sokoto in 2016, of which Abia became the pioneer state for the Project. Abia state's telecommunication market caters to almost 3.5 million active subscribers, making it the single largest provider of services in the state. Objective: The project is designed to ascertain the impact of the tele-health initiative on healthcare service coverage in Abia State. Methodology: This is a descriptive study with the quantitative and qualitative arm. The study was conducted in all the seventeen local government areas in the State. Result: 29,488 incoming calls were related to general health inquiries about basic information, counseling, and support that improved callers' knowledge and attitude towards their health, concerns, and symptoms. Also, $66.8 \%$ of all calls $(19,382)$ were for routine health information, complaints on mild everyday symptoms, chronic disease management, and follow-up care. About $29.6 \%$ of total calls (8751) were made by persons seeking information on socially stigmatizing topics and conditions.
\end{abstract}




\section{Keywords}

Tele-Health, Support Initiative

\section{Introduction}

The Abia State Tele-Health Initiative is an indigenous initiative that leverages simple and available telecommunication technology to improve access to quality health care and universal coverage of services, hence the term "Tele-health" [1]. Tele-health project is Abia's input in progressing the Universal Health Coverage mandate of the Federal Government of Nigeria, anchored on the e-Health policy of Nigeria, after its adoption at the 58th National Council on Health in Sokoto in 2016 of which Abia became the pioneer state for that project [2]. The tremendous reach and substantial influence of telecommunication technology over almost all areas of our day-to-day living, has ultimately made it an indispensable component with the potential to impact beyond our social lifestyle [3]. Abia state's telecommunication market caters to almost 3.5 million active subscribers, making it the single largest provider of services in the state [4]. The current access $(35 \%-45 \%)$ to basic healthcare services in Nigeria pales in comparison to the exponential growth being witnessed in the telecommunication sector $(110 \%)$ [4]. This strongly positions the universal telecommunication technology as a veritable tool to drive other sectors of service delivery especially the healthcare sector [5]. Access to care has been compromised by poor health-seeking behavior due to catastrophic costs incurred by out-of-pocket expenditure dominating the health system financing in the state [6]. In Abia state like most states in Nigeria, healthcare follows a three-tier system: Primary healthcare service catering to the basic health care needs of the rural population, secondary healthcare for mid-level clinical problems, and tertiary for highly specialized medical challenges [7]. More so, there are few advanced healthcare institutions of national relevance that combine teaching and research in various super-specialties [8]. Despite the fairly networked healthcare system in the State, access to healthcare especially in rural settlements is suboptimal [9]. In $2018,49.66 \%$ of the population live in rural areas [10]. However, though a greater percentage of the population live in rural areas, $75 \%$ of qualified medical doctors practice in urban areas, $23 \%$ in semi-urban towns, and only $2 \%$ in rural villages [11]. Hospital beds per 1000 persons are 0.10 in rural when compared to 2.2 in urban areas [12]. Telehealth is proven to be a suitable means of bridging this rural-urban gap and strengthen local primary health care to mitigate the current and anticipated challenges facing the system [12].

The European Commission's Health Care Telematics Program defines telehealth as "rapid remote access to 'shared' experiences, expertise using telecommunications through information technologies, regardless of when/where the patient or practitioner or relevant information is located" [13]. Despite invest- 
ment and advancement in health sciences, there are still unending and interlocking health crises [14]. In the face of emerging new diseases and global pandemics, there is a huge gap between the poor and developing countries evidenced by rising death rates and some of the world's poorest countries face declining life expectancy [15] The success achieved over the years in the health sector has been suboptimal due to weakened health systems [16]. The shape of global health in the $21^{\text {st }}$ century is highly dependent on community response [17]. Most of the health care challenges and poor health outcomes are associated with socioeconomic factors such as poverty, illiteracy, and political instability [18]. The inadequate human resources response in developing countries is threatened by brain drain and migration [19]. Secondly, in Nigeria, the chronic poor human resources development has become a recurrent decimal due to lack of political will and underbudgeting [20]. Thirdly, the increasing rate of infectious and non-communicable diseases poses a great risk to health system challenges globally [21]. Attaining universal health coverage in developing economics and politically fragile countries has not been realistic due to limited resources. The public health planners are making frantic efforts to mitigate the impact of this health crisis outlook by migrating to virtual health care support that is affordable and accessible [22]. Thus, the question of the day is "Can Virtual Healthcare Support Services Address Our Current Healthcare Challenges of Inadequate Access, Poor Outcome, and Insufficient Coverage?"

\section{Objective}

The project is designed to ascertain accessibility and coverage of healthcare services, with mobile phones irrespective of their distance to a health facility. To determine how simple and available telecommunications technologies can improve access to current and reliable health information, to show the impact of technology on the attitude and practice of the local primary healthcare workers.

\section{Methodology}

This is a descriptive study with the quantitative and qualitative arm. The study was conducted in all the seventeen local government areas in the State. The target population are persons residence in Abia State using the Glo communication network. A Call Center manned by Medical Doctors provided remote clinical healthcare support services to PHC providers in local communities in the state. The call center through the local healthcare worker offer, prompt consultations, health information and education to people in the comfort, convenience, and confidentiality of their own spaces, homes, offices, and shops. Purposeful sampling was used to select 17 health facilities in the LGA for the study. The project selected project focal persons for each PHC's, and equipped the center with, desktop computers, phones, data collection cards, and registered post-paid Glo communication SIM card. The focal persons assist the client to the call center for diagnosis, management, and referrals. The prepaid Glo communication card guarantees the client access to call centers and doctors. The study tends to measure 
the impact of the project on access to care especially for those who cannot afford medical consultation due to cost and availability. A pretested questionnaire was developed to collect the number of calls, presenting complaints, and diagnoses. The data was collected in excel and exported to SPSS for analysis. Four in-depth interviews were conducted for the 12 clients and 24 health care workers working at a different level of the project. The interviews were conducted, transcribed verbatim, coded, and thematically analyzed.

\section{Result}

At the end of a 12-months pilot, comprising of 292 PHCs, the Abia State TeleHealth Initiative has recorded a total of 29,488 incoming phone calls. In the calls comprising of follow-up and returned calls, $58 \%$ were females while $42 \%$ were males. $54.9 \%$ of the calls lasted for 10 minutes while $45.1 \%$ were below $10 \mathrm{mi}$ nutes. $22 \%$ of the total calls were made between $5 \mathrm{pm}$ and $10 \mathrm{pm}$ while most of the calls $78 \%$ were done during working hours (Figure 1). However, $48 \%$ of the calls were made from offices and shops. $81 \%$ of the total callers $(22,413)$ were satisfied with the PHC worker's response while 19\% were dissatisfied with PHC's workers' response. $98.5 \%$ of the calls were from Abia State while $1.5 \%$ of the callers were from outside Abia state (Abuja, Adamawa, Akwa Ibom, Anambra, Bayelsa, Delta, Ebonyi, Enugu, Gombe, Imo, Kaduna, Kogi, Lagos, Niger, Ogun, Ondo, and Rivers). 29,488 incoming calls were related to general health inquiries about basic information/counseling and support that improved callers' knowledge and attitude towards their health, concerns, and symptoms. $66.8 \%$ of all calls $(19,382)$ were for routine health information, complaints of mild everyday symptoms, chronic disease management, and follow-up care.

About $29.6 \%$ of total calls (8751) were made by persons seeking information about socially stigmatizing topics and conditions (Sexual and Reproductive Health problems, HIV/AIDS, other STDs, Infertility, Erectile dysfunction, Contraception, Pregnancy, and Abortion/Mental Health issues, illicit drug abuse, depression, economic and education co-stressors), who may have received care in the absence of confidential access to healthcare. Around $1.1 \%$ of the calls (324) were seeking correct, reliable information (prospective and retrospective) on public health diseases outbreaks, mostly Lassa fever (rats), cholera, cerebrospinal meningitis, and ebola, as regards their etiology, mode of transmission, fatality, preventive and curative protocols. About 3.5\% (1031) of all calls were not healthrelated, either to test the line, the wrong number, ask geographic directions, complaints about life in general. However, $8 \%$ of the total calls visited the facilities as directed by the call center (Figure 1 ).

Qualitative findings: The in-depth interview conducted commended the project. Excerpts from the interview show that the health workers benefitted from the project personally and professionally. There was an improvement in the healthseeking behavior (real and virtual) which was reflected in the client flow. Availability of expanded care options, diagnosis, and management. This was succinctly 


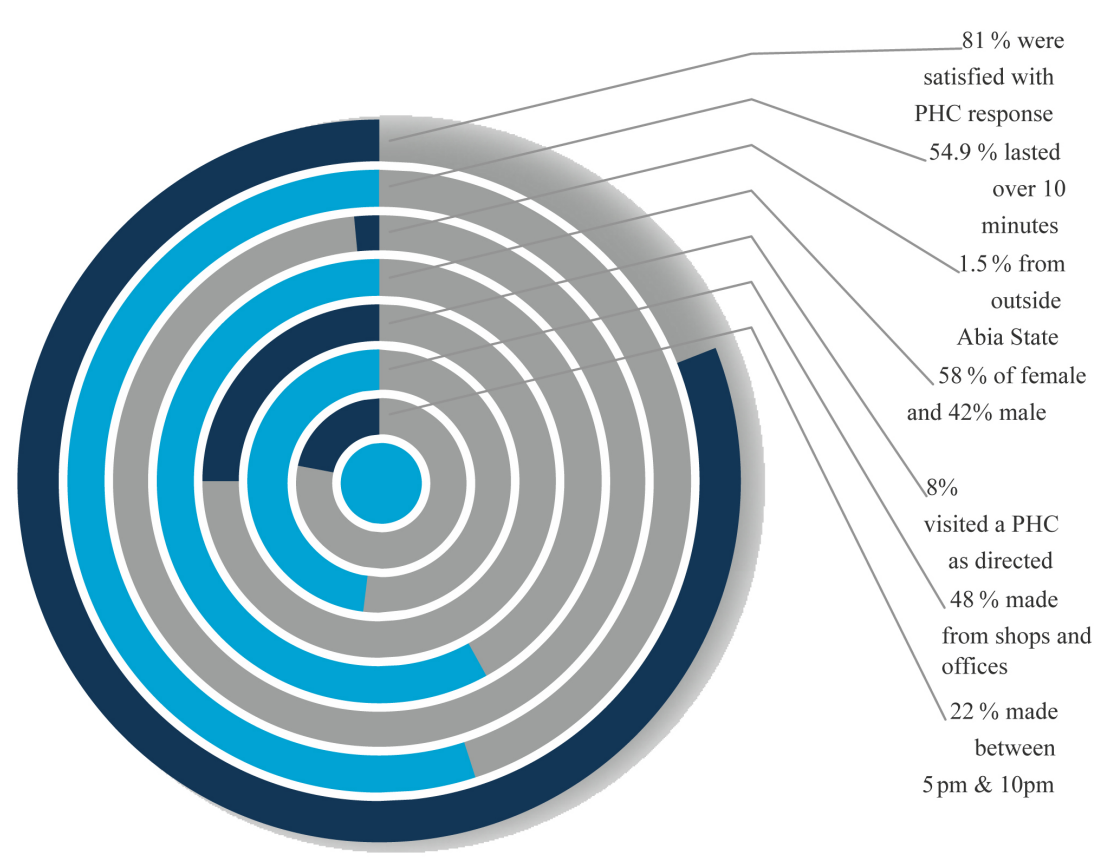

Figure 1. Callers' response.

put by one OIC as "The AbSTHi project has improved both uptake and adherence to PHC services especially immunization, as mothers can inquire about the availability of particular vaccines before they turn up with their babies to the facility, consequently, more babies were immunized in line with immunization schedules, this project has improved virtually all activities in the PHC” [OIC1]. There was better reliability and responsiveness of the local health system to visitors, a renewed sense of job satisfaction, and stronger community ties. The study revealed greater independence and autonomy which translated to enhanced workers competence and proficiency. "I think I am the person that has benefitted the most from this initiative, it gives me joy and fulfillment anytime I call the center for support" [OIC2]. It has given us the healthcare workers a lot of strength and confidence, we had a patient with a high BP of 190/100 and with the support from the call center, and we were able to manage the patient, even though we were asked to eventually refer the patient. "there is a sense of partnership when patients see us communicating with the doctor on their ailment, they felt excited in with our conversations with the call center, they feel were are empathic and doing our best for them" [OIC3]. The project provided a platform for capacity building as most of the health workers had better knowledge on management of diverse medical conditions. According to one of the respondents, "in my facility, there is better understanding in handling of cases and most of the calls came from outside Abia State, neighboring states, Imo and Anambra" [OIC4].

\section{Conclusions}

The most common application of Tele-Health is the use of telecommunication 
technologies like simple telephones to support individuals and institutions on both personal and population health maintenance, preventive, rehabilitative, and curative health care, by creating easy access to reliable health information, transferring content not casualties, moving potentials not patients. DIAL-A-DOCDIRECT is an optimistic, veritable tool for reliable health information dissemination, health data gathering and exchange, effective community health policing, and reliable monitoring \& evaluation of PHC service providers and provisions; with the singular objective to further strengthen and optimize our existing local health systems.

The AbSTHi plans within the innovative framework of a mutually beneficial partnership, improved inter-sectoral (health, ICT, Communication, Science and Technology) collaboration in PHC delivery, building on the established relationship between political classes, grassroots communities, major stakeholders, and expert technocrats (inclusive of local health care workers). The project enhanced a functional integration at all levels of the project and ensured effective, seamless, and holistic transfer of ownership of the AbSTHi to the Abia State Ministry of Health. The initiative has taken Abia State a step closer to Universal Health Care for all; however, have some of the calls from other states like Taraba and Edo states.

Recommendations: The Abia Tele-health initiative is a proven complementary approach to improving access to quality and affordable health care in Abia State. There is a need to develop state policies and guidelines that will support standardization of the practice and possible scale-up to the third phase of the project. The federal ministry of health should adopt and scale up the findings to other states in the country that are expressing interest. The State Ministry of Health should implement the tele-health initiative in line with national guidelines, best practices and integrate the concept to basic primary healthcare services in the primary health care facilities, such as routine immunization, Antenatal care, HIV as well as treatment of common diseases. The tele-health initiative should be incorporated in the basic primary health training manual and other medical curriculums. The state ministry of health should approve funding to support research on innovative advances on tele-health initiatives, as well as monitor the evolving progression of tele-health and its implication for the future.

\section{Conflicts of Interest}

The authors declare no conflicts of interest regarding the publication of this paper.

\section{References}

[1] Black, A.D., Car, J., Pagliari, C., Anandan, C., Cresswell, K., Bokun, T., McKinstry, B., Procter, R., Majeed, A. and Sheikh, A. (2011) The Impact of eHealth on the Quality and Safety of Health Care: A Systematic Overview. PLoS Medicine, 8, e1000387. https://doi.org/10.1371/journal.pmed.1000387

[2] World Health Organization (2020) Global Diffusion of eHealth: Making Universal 
Health Coverage Achievable.

https://www.afro.who.int/publications/global-diffusion-ehealth-making-universal-h ealth-coverage-achievable

[3] Deloitte (2014) How Technology Is Transforming Health and Social Care. Deloitte Centre for Health Solution, UK.

https://www2.deloitte.com/content/dam/Deloitte/uk/Documents/life-sciences-healt h-care/deloitte-uk-connected-health.pdf

[4] SkyTechNG Integrated Services (2020) Abia State GSM Number Database. https://www.gsmnumberdatabase.skytechng.com/abia-state-gsm-number-database

[5] Alabi, G.A. (1996) Telecommunications in Nigeria. http://www.africa.upenn.edu/ECA/aisi_inftl.html

[6] Abuduxike, G., Asut, O., Vaizoglu S.A. and Cali, S. (2020) Health-Seeking Behaviors and Its Determinants: A Facility-Based Cross-Sectional Study in the Turkish Republic of Northern Cyprus. International Journal of Health Policy, 9, 240-249. https://doi.org/10.15171/ijhpm.2019.106

[7] Federal Ministry of Health (2016) National Health Policy 2016: Promoting the Health of Nigerians to Accelerate Socio-Economic Development. Federal Ministry of Health, Abuja.

https://naca.gov.ng/wp-content/uploads/2019/10/National-Health-Policy-Final-cop y.pdf

[8] Reid, P.P., Compton, W.D., Grossman, J.H., et al. (2005) 4, Information and Communications Systems: The Backbone of the Health Care Delivery System. Washington D.C. https://www.ncbi.nlm.nih.gov/books/NBK22862/

[9] Aregbeshola, B. (2019) Health Care in Nigeria: Challenges and Recommendations. https://socialprotection.org/discover/blog/health-care-nigeria-challenges-and-reco mmendations

[10] Index Mundi (2019) Nigeria-Rural Population (\% of the Total Population). https://www.indexmundi.com/facts/nigeria/indicator/SP.RUR.TOTL.ZS

[11] American Hospital Association (2001) The Health Care Workforce Shortage and Its Implication for America's Hospitals. AHA Workforce Survey Results. American Hospital Association, Chicago.

https://www.aha.org/guidesreports/2001-06-01-trendwatch-hospital-workforce-sho rtage-immediate-and-future.

[12] Singh, M. and Das, R.R. (2010) Utility of Telemedicine for Children in India. The Indian Journal of Pediatrics, 77, 73-75. https://doi.org/10.1007/s12098-009-0292-x

[13] European Health Telematics Association (2008) Sustainable Telemedicine: Paradigms for Future-Proof Healthcare.

http://armtelemed.org/resources/48EHTEL_Briefing_Paper_Sustainable_Telemedic ine.pdf

[14] Chen, L., Evans, T., Anand, S., Boufford, J.I., Brown, H., Chowdhury, M., Cueto, M., Dare, L., Dussault, G., Elzinga, G. and Fee, E. (2004) Human Resources for Health: Overcoming the Crisis. The Lancet, 364, 1984-1990. https://doi.org/10.1016/S0140-6736(04)17482-5

[15] Akmal, M. and Pritchett, L. (2019) Learning Equity Requires More than Equality: Learning Goals and Achievement Gaps between the Rich and the Poor in Five Developing Countries. Center for Global Development, Washington DC. https://doi.org/10.35489/BSG-RISE-WP_2019/028

[16] Safran, D.G., Tarlov, A.R. and Rogers, W.H. (1994) Primary Care Performance in Fee-for-Service and Prepaid Health Care Systems: Results from the Medical Out- 
comes Study. JAMA, 271, 1579-1586.

https://doi.org/10.1001/jama.1994.03510440039030

[17] Crotty, J.B. and Brown, T. (2007) An Urgent Challenge: New Training Opportunities for Junior Medical Officers. Medical Journal of Australia, 186, S25-S27. https://doi.org/10.5694/j.1326-5377.2007.tb00962.x

[18] Modey, E.U. (2011) A Survey of Problems Associated with underdeveloped Economies. Clements University, British West Indies.

http://stclements.edu/grad/gradedwa.pdf

[19] Scheffler, R.M., Campbell, J., Cometto, G., Maeda, A., Liu, J., Bruckner, T.A., Arnold, D.R. and Evans, T. (2018) Forecasting Imbalances in the Global Health Labor Market and Devising Policy Responses. Human Resources for Health, 16, Article No. 5. https://doi.org/10.1186/s12960-017-0264-6

[20] Adeloye, D., David, R.A., Olaogun, A.A., Auta, A., Adesokan, A., Gadanya, M., Opele, J.K., Owagbemi, O. and Iseolorunkanmi, A. (2017) Health Workforce and Governance: The Crisis in Nigeria. Human Resources for Health, 15, Article No. 32. https://doi.org/10.1186/s12960-017-0205-4

[21] World Health Organization (2020) Noncommunicable Diseases. World Health Organization, Geneva.

[22] World Health Organization (2010) TELEMEDICINE in the Member States. World Health Organization, Geneva.

https://www.who.int/goe/publications/goe_telemedicine_2010.pdf 